\title{
An international perspective on training in child and adolescent psychiatry
}

\author{
Peter Deschamps ${ }^{1} \cdot$ Brian Jacobs $^{2}$
}

Published online: 16 January 2020

○) Springer-Verlag GmbH Germany, part of Springer Nature 2020

You may be familiar with the $10,000 \mathrm{~h}$ rule that states that for an average human being, it just takes that much time to get sufficiently good at a certain rather difficult skill. It seems to apply to arts, sports, and most professional activities. The various papers in this issue [1-9] of ECAP offer a perspective on how our trainees in Europe as well as other parts of the world spend their 10,000 h. They offer an overview of differences and similarities in length and content of training, but also on how we guide our trainees through their personal and professional development and help them spend those $10.000 \mathrm{~h}$ in the most productive and fruitful way to prepare to attend to children's mental health needs in the future.

A picture emerges with a lot of similarities between child and adolescent psychiatry (CAP) training across the world. First, taking the assumption that our trainees spend $40 \mathrm{~h}$ a week, 50 weeks a year and around 5 years on their total training programs, most of them will be in the vicinity of the $10,000 \mathrm{~h}$ rule by the end of their training when hours spent in general psychiatric training are included. That is reassuring, but should not be taken for granted in a time, where in most areas, guided by a shortage in the workforce and financial considerations, there is a tendency towards an increase in "efficiency" and shortening in total training time. Second, in most training programs, the three pillars and traditions of adjacent professions from which CAP emerged are clearly present. Adult psychiatry and psychotherapy are part of the curriculum almost everywhere, and so are pediatrics as well as a tradition in developmental psychology and cooperation with social care and educational systems. One initiative that we were surprised to read about was the Triple

Peter Deschamps

P.K.H.Deschamps@umcutrecht.nl

1 Department of Psychiatry, Utrecht University Hospital, Postbus 85500, 3508 GA Utrecht, The Netherlands

2 South London and Maudsley NHS Foundation Trust, London, UK
$\mathrm{P}$ training track in the US, not to be confused with the Triple $\mathrm{P}$ parenting program from Australia. In this program, a registration in CAP, general psychiatry, as well as pediatrics can be obtained at the end of training. A good question for the future is whether we need to strive towards a situation where every child and adolescent psychiatrist has as much background in each of these areas or allow for individual differences based on the trainee's preferences and talents. In a similar fashion, individual profiles with one or more in-depth training in scientific research, psychotherapy, or teaching skills may be considered. Third, as seems to be the case in more areas in society these days, we seem to be struggling with a balance between self-guidance and trust on one hand and quality control on the other hand. In our training programs, this becomes visible in valuable and necessary attempts to develop international European guidelines for a curriculum framework with a list of need-to-know and musthave-done for every child and adolescent psychiatrist as well as self-assessment and evaluation of knowledge and skills. These are to support country or other training bodies when setting their competence-based curricula. Besides training to achieve these clear set goals, we want to keep some space and time for our trainees for serendipity in training; some of our own valuable teaching and learning experiences were not planned ahead but emerged in a more natural way during the course of training. Fourth, we are trying to work to improve recruitment as well as retention. Again, this is something not unique to our profession. Both may be more closely related than expected at first glance. A life-long learning perspective including basic medical training, post-graduate CAP training, and continuous medical education suggests that we could start thinking about continuity of training even more than we do today. Of note, training other medical colleagues in CAP may not only help us to recruit future talents for CAP, but may also help us to lay a basis for future cooperation, consultation, and broaden the workforce to enhance child and adolescent mental health services. It is likely to help patients. 
Of course, there are also many differences in local training programs. The papers in this issue make a good start to put them into perspective with respect for cultural background, economic circumstances, organization of mental health care, and cooperation of child and adolescent psychiatrists together with other professionals. Despite and because of this wide variety, a further increase in international collaboration in training initiatives may help us better face future challenges in training. As has happened in scientific research in medicine in the past decades, those aiming to increase their effectiveness in training can be more efficient when they cooperate, share materials and insights on what we teach and how we teach it. Luckily for us, as child and adolescent psychiatrists, we have gained some experience in taking a life-long developmental perspective, in putting ourselves in the shoes of people with a different background, in cooperating with complex systems and in balancing autonomy and guidance. The development of a trusting, well-functioning collaborative network around training child and adolescent psychiatrist may be a task that takes $10,000 \mathrm{~h}$, but it is likely to have great benefit. The first steps taken by the UEMS-CAP section have resulted in enthusiastic and encouraging responses. When this issue of European Child and Adolescent Psychiatry has tickled your curiosity as a reader about your own chances to contribute, please join us to explore teaching CAP trainees.

\section{References}

1. Rao P, Caunt JN, Wong JWY et al (2019) Eur Child Adolesc Psychiatry. https://doi.org/10.1007/s00787-019-01422-5

2. Barrett E, Jacobs B, Klasen H et al (2019) Eur Child Adolesc Psychiatry. https://doi.org/10.1007/s00787-019-01416-3

3. Gregoric Kumperscak H, Clausen C, Anagnostopoulos D et al (2019) Eur Child Adolesc Psychiatry. https://doi.org/10.1007/ s00787-019-01362-0

4. Hendrickx G, De Roeck V, Russet F et al (2019) Eur Child Adolesc Psychiatry. https://doi.org/10.1007/s00787-019-01309-5

5. Clausen CE, Bazaid K, Azeem M et al (2019) Eur Child Adolesc Psychiatry. https://doi.org/10.1007/s00787-019-01360-2

6. Hunt J, Reichenberg J, Lewis AL et al (2019) Child and adolescent psychiatry training in the USA: current pathways. Eur Child Adolesc Psychiatry. https://doi.org/10.1007/s00787-019-01402-9

7. Scivoletto S, Fondello MA, Otoch LN et al (2019) Eur Child Adolesc Psychiatry. https://doi.org/10.1007/s00787-019-01454-x

8. Kommu JVS, Jacob P (2019) Specialty training in child and adolescent psychiatry in India. Eur Child Adolesc Psychiatry. https ://doi.org/10.1007/s00787-019-01407-4

9. Zheng A et al (2019) Training status of child psychiatrists in China. Eur Child Adolesc Psychiatry. https://doi.org/10.1007/ s00787-019-01453-y 